\title{
Benign Supraglottis Neoplasm
}

National Cancer Institute

\section{Source}

National Cancer Institute. Benign Supraglottis Neoplasm. NCI Thesaurus. Code C8414.

A non-metastasizing neoplasm that arises from the supraglottis. 